$$
\begin{aligned}
& \text { تقييم أداء اصناف من الكراويا Carum carvi L تحث ظروف العراق } \\
& \text { علي فدعم عبدالله المحمدي } \\
& \text { استاذ مساعد } \\
& \text { وحدة الزراعة النسيجية والتقانة الاحيائية- مركز دراسات الصحراء- جامعة الانبار - الرمادي- العراق. } \\
& \text { Agge_biplot@yahoo.com }
\end{aligned}
$$$$
\text { المستخلص }
$$

ان تقدير طبيعة ودرجة التباعد الوراثي لصفات مختلفة قد ينفع في وضع برامج تهجين وتضريب لاسترداد الاتحادات الجديدة. لذا استخدمت طريقة التحليل الصوري Metroglyph analysis وتحليل التباين لتقدير التباعد الوراثي لسبعة تراكيب وراثية من محصول الكراويا فقد طبقت تجرية حقلية في الموسم الشتوي لعام 2012/2011 بثلاثة مكررات. سجلت البيانات لصفات كارتفاع النبات و عدد الافرع وعدد النورات الرئيسة بالنبات وقطر النورة الرئيسة وعدد النورات الثانوية وحاصل النبات الفردي.

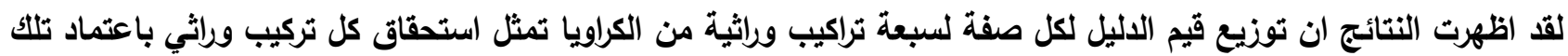
الصفة. اذ ان اداء كل تركيب وراثي يتمثل بقيم الدليل الكلي لكل الصفات لذلك الصنف فقد اعطى التركيبان الوراثيان بري وموصل اعلى قيم دليل 16 لكل منهما. كما يبين رسم التحليل الصوري ثلاث مجموعات من التراكيب الوراثية من الكراويا. بذا يمكن ان يستتنج ان تقانة التحليل الصوري صنفت بسهولة التراكيب الوراثية الى مجاميع وامكانية استقراء اداء تلاك التراكيب الوراثية بقيم الاليل. لذا يمكن الايصاء بتطبيق تضريب او تهجين بين افراد من مجاميع مختلفة لا بين افراد من نفس المجموعة لاعطاء افضل نتائج من الصفات الاقتصادية. اذ تميزت التراكيب الوراثية بري و موصل وسوري ومنتخب الأبن جيل1(مجموعة2) ويلدي (مجموعة3) فقد يمكن تطبيق تضريب بين اي من افراد المجموعة2 مع التركيب الوراثي بلاي

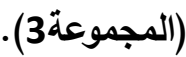
الكلمات المفتاحية: الكراويا، تراكيب وراثية، التحليل الصوري، قيم الدليل، مجموعات.

\title{
EVALUATION OF PERFORMANCE FOR CARAWAY (Carum carvi L.) CULTIVARS OVER IRAQI ENVIRONMENTS
}

\section{A. F. Almehemdi}

Assist.Lecturer

Tissue Culture and Biotechnology Unit- Center of Desert Studies (CDS)- University of Anbar-Rammadi-IRAQ Agge_biplot@yahoo.com

\section{ABSTRACT}

Assessment of genetic diversity for various traits would contribute in hybridization projects in order to recover aspired recombinants. Therefore, metroglyph analysis and ANOVA were conducted out to estimate genetic diversity among seven caraway genotypes. Field experiment was applied in winter season of 2011/2012 with three replicates. Consequently, data were recorded on plant height, branches no., umbels no. umbels diameter, no. of umbellets and plant yield. Results showed that allotting of index scores for each trait of seven caraway genotypes represented the worth of the genotype in respects to the trait which the performance of genotype is represented by total index score for all traits of that genotype. Thus, Bery and Mosul genotypes ascertained the highest index scores of 16, for each one. Moreover, Metroglyph scatter diagram revealed three groups of caraway genotypes. Therefore, it could be concluded that metroglyph technique simply classified genotypes to groups and had potentiality to interpret genotypes performance regarding the index scores. Thus, it could be recommended to apply crossing or hybridization between individuals from different groups alternatively to individuals from same group. Genotypes of Bery, Mosul, Sury and selectedF1 (Group2), and Balady (Group3) were distinct which possible to apply crossing between one of group2 individuals with another one of group3.

Keywords: Caraway, Genotypes, Metroglyph analysis, Index scores, Groups. 
الموصـوفة من قبل Anderson (2) فهي سـهلة الاستخدام والتطبيق. اذ طبق العديد من الباحثثن هذه الثقانة في تقييم

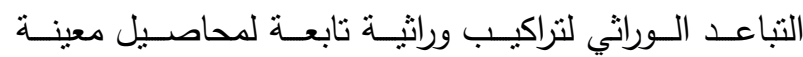
كالباحث Datta واخرون (7) فقد بين امكانية استخدام هذه لبه لبه

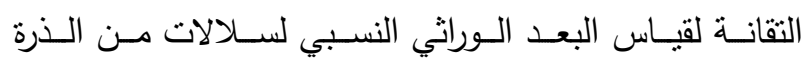

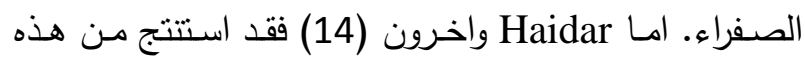
التقانـة امكانيـة التهجين بـين تراكيب وراثيـة مـن القطن مـن فئن

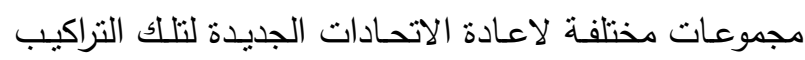

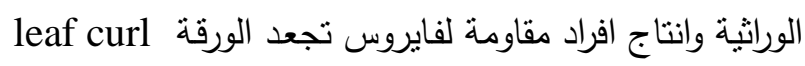

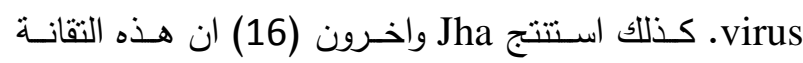
يمكن ان تستخدم لوضـع برامج تضـريب بين تراكيب وراثيـة

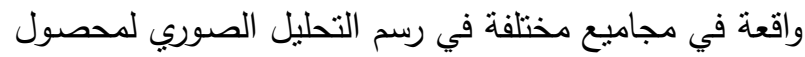

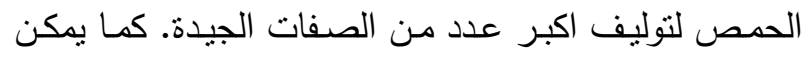

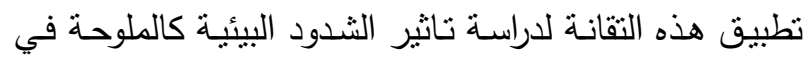

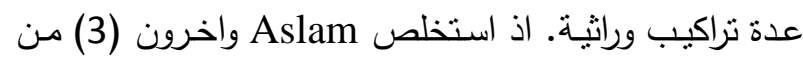
هذه التقانة عدة تراكيب وراثية من محصول القطن واقعة في وراهي

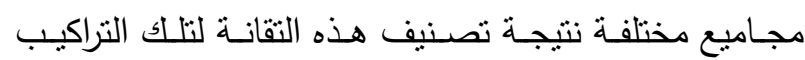
الوراثيـة وامكانيـة التزاوج بينها للحصـول على تراكيب وراثية متحملــة للملوحسة. وبـنفس الطريقـة اسـتنتج (17) امكانية التضريب بين نراكيب وراثية من النبات الطبي

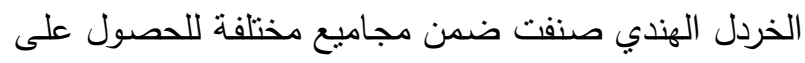
اعلى تباين لتوليفات جيدة من صفات اقتصـادية معينة. ان التراكيب الوراثيـة ذات الصـفات المرغوبـة قد تكون ملائمـة

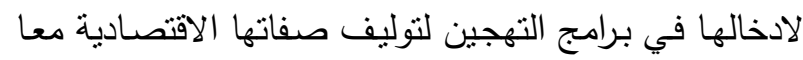

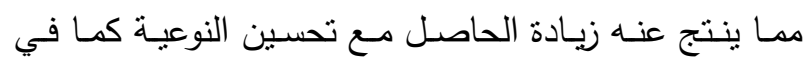
اصناف فستق الحقل (9). ان هذه التقانة يمكن ان تستخدم

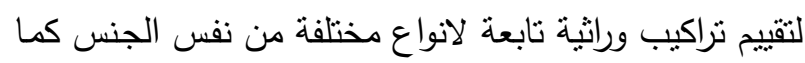

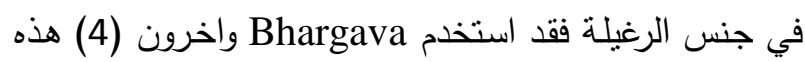
التقانة لتقييم تراكيب وراثية تابعة لنوعين من الرغيلة هما النوع

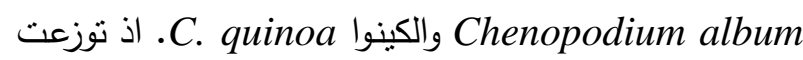
تراكيبها الوراثيـة في مجاميع مختلفـة فقد اثـار الـى امكانيـة

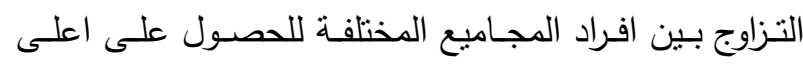

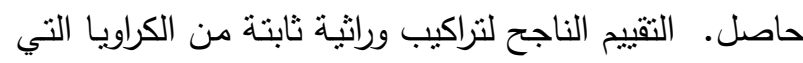
تستخدم مستقبلا في برامج التربية لتطوير تراكيب وراثية واعدة

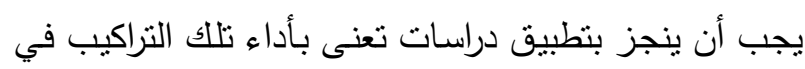

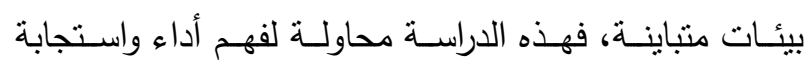

المقدمـة

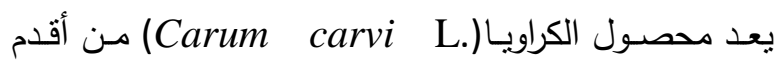

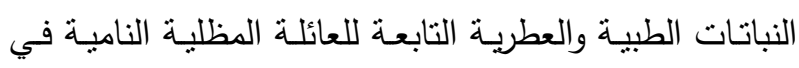
آسيا وأوروبا وأمريكا الثمالية (22). فقد استخدمت في بلدانها

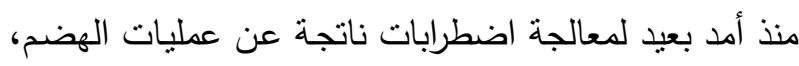
كما أنها توصف عادة كمدرر (18) وكمضاد لارتفاع السكر

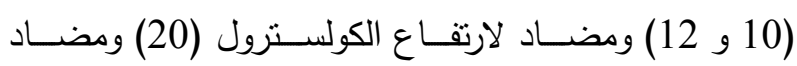
للسـرطان (21) وكمضــاد حيـوي للبكتريـا (25 و 26) وفي ومي تغذية طائر السمان الياباني (15) وفي زيادة إفراز هورمونات

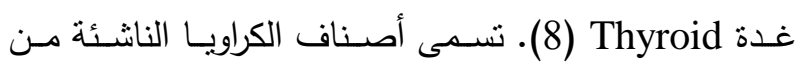

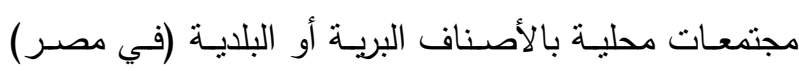
لتصبح مصدر أصناف جديدة منتخبة إلا أنها منباينة وراثياً.

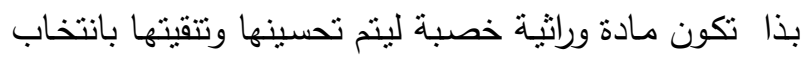

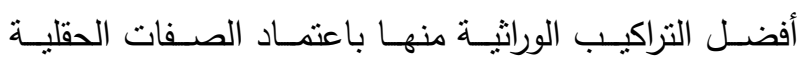

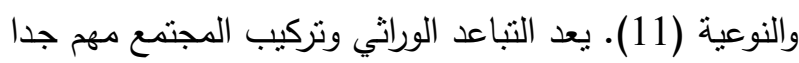

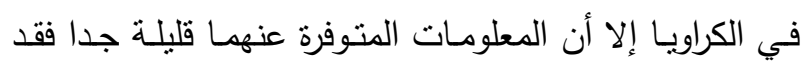

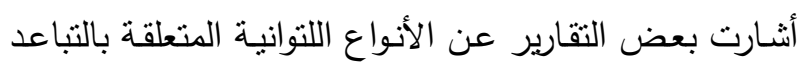
والثباتيـة خارج الموقع ex situ الخاصـة بالصفات المظهرية

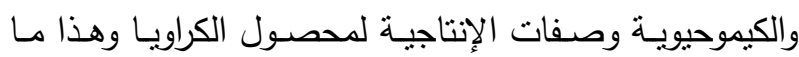
يسمى Cenopopulations النامية بريا ( 6 و 23 و 24).

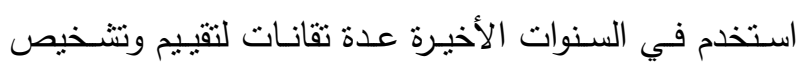
العلاقات والتتوع الوراثي منها التقانـات الجزيئية (5 و 19)، فقد استخدموا تقانـة RAPD لتقيم التباعد الوراثي والصفات الكميـة لمجتمعات مـن الكراويـا. امـا Ferrie وآخـرون (13)

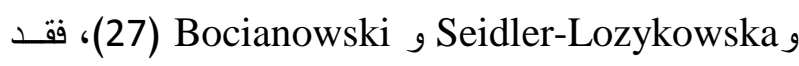
استخدموا الطرائق التقليديـة لتقييم تراكيب وراثيـة من الكراويـا مزروعة في بيئات مختلفة إلا أن الطرائق التقليدية تحتاج إلى تئي

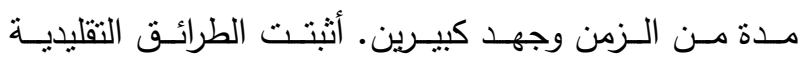
والجزيئية إن التتوع الوراثي ناتج عن تباين في الظروف البيئية

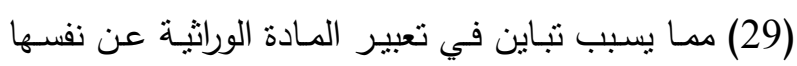
بشكل واضـح. بذا فهذه التباينات تسبب اختلافات كبيرة في نياني

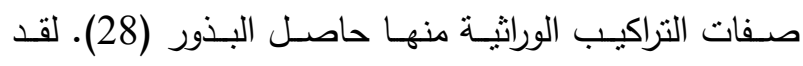
استخدمت عدة نقانات احصائية لتصنيف وتقييم نراكيب وراثية

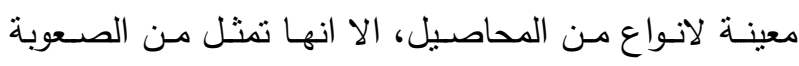

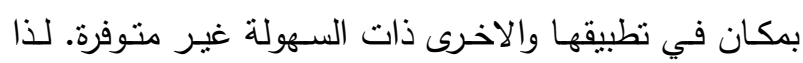

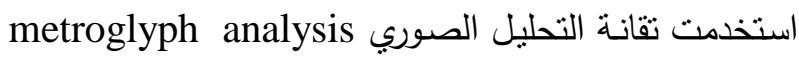


شعب متساوية اعطت درجات هي منخفضة ومتوسطة وعالية فقد يعتمد طول الثـعاع على قيم دليل(1 و 2 و 3) التركيب

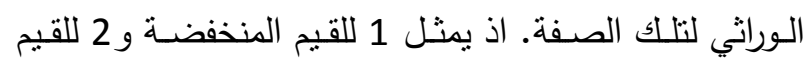

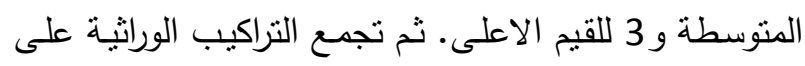

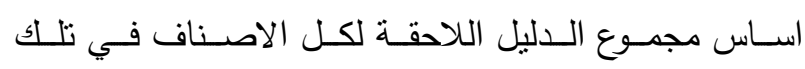
المجموعة. استخدم موقع الرمز الصوري والاشعة لتقيم نمط

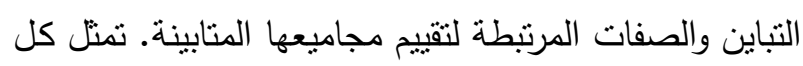
صنف بالرمز الصوري فالرمز يمثل نقطة تقاطع المنوسطات

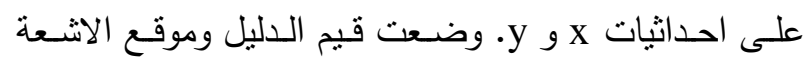

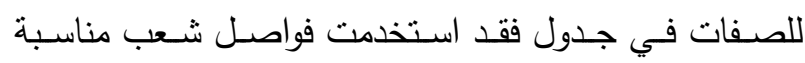

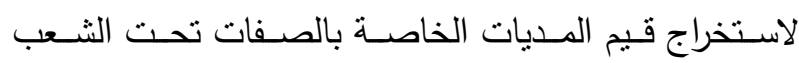

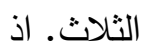

$$
\text { .......1A }=\frac{W u-W l}{3}
$$$$
\mathrm{X}_{1}=\mathrm{A}+\mathrm{V}_{1} \ldots \ldots .2
$$

في كل الصفات، فـان قيم المتوسطات X

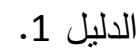
$\mathrm{X}_{2}=\mathrm{X}_{1}+\mathrm{A}$ قيم منوسطات المشاهدات الواقعة بين X و $X_{1}$ و تجمع تحت

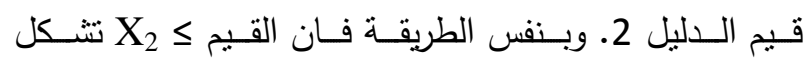
المجموعة الاكبر تحت قيمة دليل 3. لقد حسبت متوسطات كل مجموعة لفئات مختلفة وقيم دليلها لترجمة النتائج.

\section{النتائج وإلمناقشة مبهة}

تتـير نتـائج جدول 1. ان كل التراكيب الوراثيـة لمحصـول

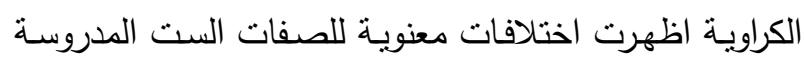
فقد سجل التركيب الوراثي سوري اعلى منوسط لارتفاع النبات

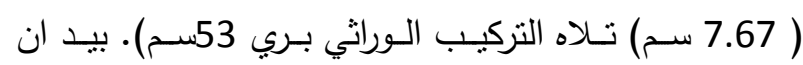

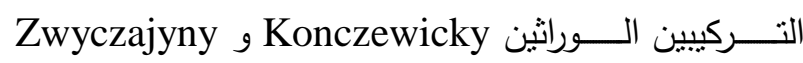
اعطيا اقل منوسطين لارتفاع النبات (10سم) لكل منهما. اما

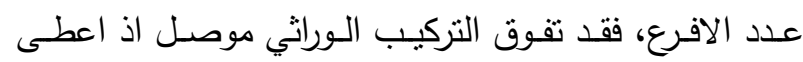

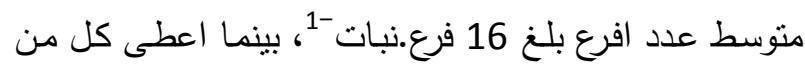

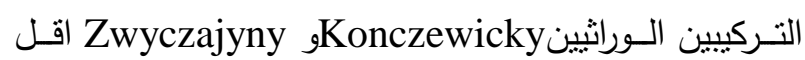
متوسط لعدد الافرع بلــ 5 فرع.نبـات -1. لقد اثـارت نتائج

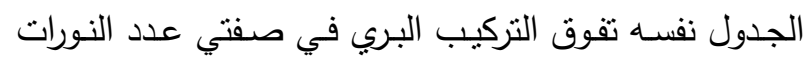
الرئيسة وقطر النورة الرئيسة فقد بلغ منوسطهما 41.67 نورة

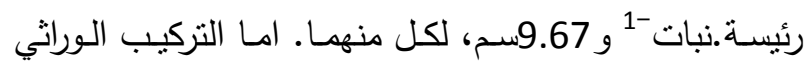
بلدي فقد تفوق في صفتي عدد النورات الثانويـة وحاصـل النبات الفردي. اذ كان منوسطاهما 16.33 نورة ثانويـة.نورة
(التباين المظهري) لسبعة اصناف من الكراويـا لتأكيد أهميـة تداخل الصـفات الثـكلية للتركيب الـوراثي في بـرامج التربيـة

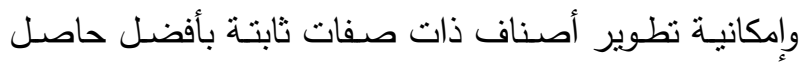

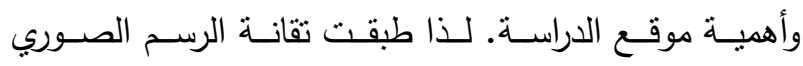

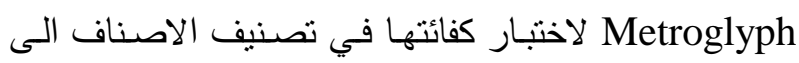

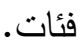
المواد والطرائق نفـت تجربـة حقليـة في احد الحقول الخاصــة في الفلوجـةا محافظة الانبار خلال الموسم 2011/2012. طبقت التجربة باستخدام تصميم القطاعات العشوائية الكاملة بثلاثة مكررات. إذ تم تحضير الأرض بحراثتها حراثثين متعامدتين ونسويتها

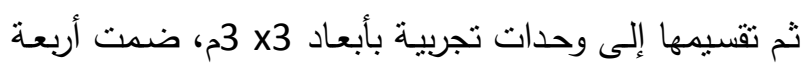

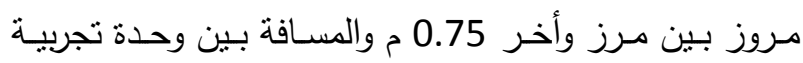

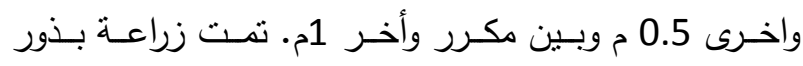
اصناف الكراويا في 2011/10/30 بمسافة 25 سم بين جورة وأخـرى على المـرز . أجريــت كافـة عمليـات خدمـة التربـة والمحصسول بإنباع المحمدي (1). حصدت المرات النباتات بتاريخ

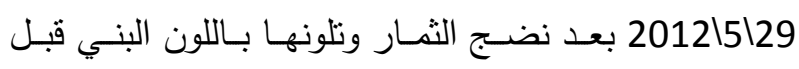

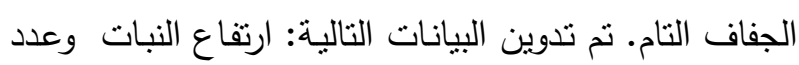

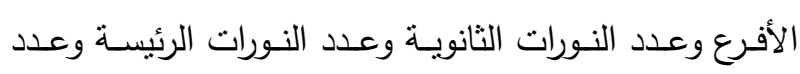

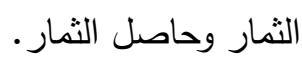
التحليل الإحصائي أخضــت البيانـات للتحليـل الإحصــائي باسـتخدام برنـامـج

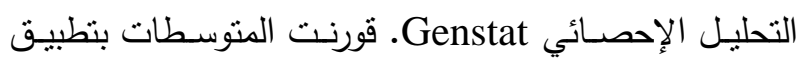
تحليل تباين باتجاهين(ANOVA) المتبوع باختبار اقل فرق معنــوي L.S.D للمتوســــات. اعتبــرت الفروقــات بــين

المتوسطات الفردية معنوية عند مسنوى احتمال P>0.05.

\section{Metroglyph analysis التحليل الصوري او بالرموز} استخرج متوسط كل صنف لكل من الصفات اعلاه وسجل مدى قيم كل صفة. ادخلت قيم تلك المتوسطات في تحليل صوري او بالرموز (metroglyph analysis) المقترح من (د) في

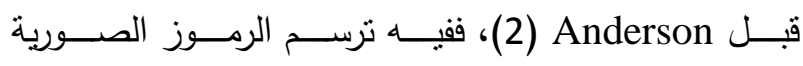
على اسـاس متغيـرين لصـفتين. اذ يـتم اختيـار (glyphs) الصفتنن ذواتي اعلى تباينين كمحورين هما X و y. y. اما بقية الصنية الصفات فيعبر عنها باشعة على كل رمز صوري. فكل شعاع دئن يمثل صفة خاصـة تتـتج من قسمة مدى التباين الى ثـلاث 
كـــا تضـمن الجـدول نفسـه مــديات متوسـطات الصـفات المحسـوبة حسب الفئسة التصـنيفية فقد كانـت في الفئسة1:

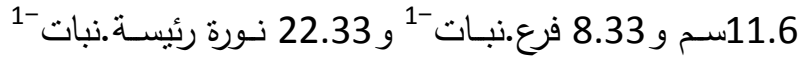

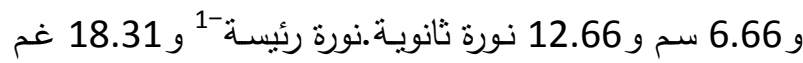
لصفات ارتفـاع النبات وعدد الافرع وعدد النورات الرئيسـة وكنة

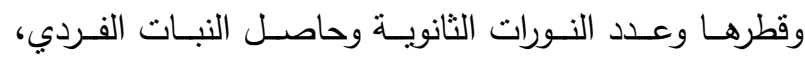
بالتزتيب. اما في الفئة3 (اكبر من x) فقد كانت: 44.32 سم

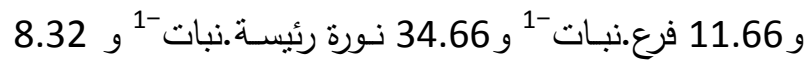

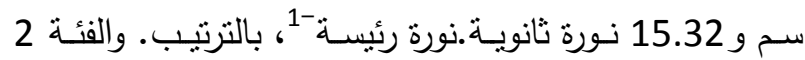

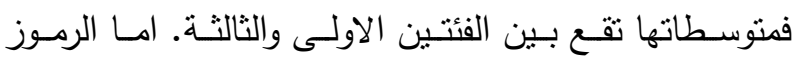

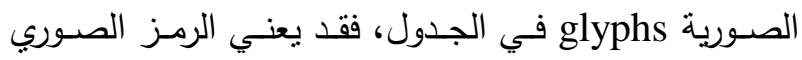

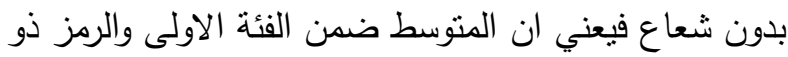

رئيسة ${ }^{1-} 31.84$ غم لكل منهما. بيد ان التركيبين الوراثيين Konczewicky منوسطات لصفات عدد النورات الرئيسة وقطر النورة الرئيسة

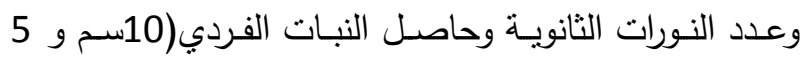
فرع.نبات -1 و 10 نورة رئيس.نبات -1 و وكسم و 10 نور ثانوية.

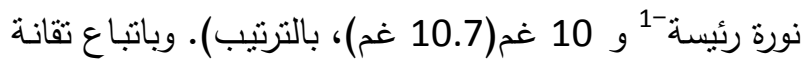
metroglyph

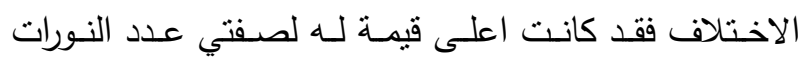
الثانويـة وحاصل النبات الفردي 12.1 و و12.7 بالترتيب لكل علدي

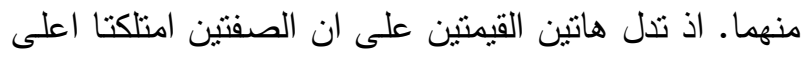

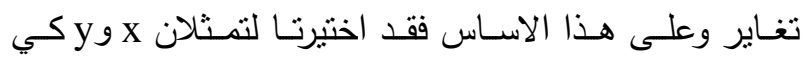
ترسمان لتجميع النراكيب الوراثيـة في ذلك الرسم(شكل 1.

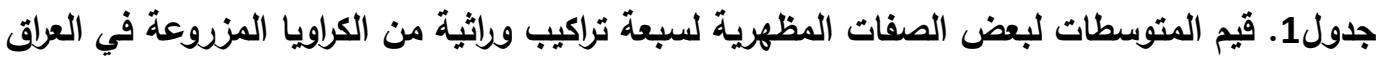

\begin{tabular}{|c|c|c|c|c|c|c|}
\hline القرديـــــل النبـــــات & الثانوية النورات & قائطـر النــورة) & الرئيسة النورات & عدد الاضرع & النباتف(سم) ارتفــاع & التراكيب الوراثية \\
\hline 24.28 & 15.00 & 8.33 & 10.67 & 7.67 & 52.67 & منتخب جيل1 \\
\hline 31.84 & 16.33 & 8.33 & 13.33 & 8.33 & 52.67 & بلدي \\
\hline 19.14 & 15.67 & 9.67 & 41.67 & 11.00 & 53.00 & بري \\
\hline 21.05 & 16.00 & 8.50 & 34.00 & 16.00 & 47.00 & موصل \\
\hline 19.88 & 13.00 & 8.33 & 28.33 & 8.00 & 57.67 & سوري \\
\hline 10.70 & 10.00 & 5.00 & 10.00 & 5.00 & 10.00 & Zwyczajyny \\
\hline 10.00 & 10.00 & 5.00 & 10.00 & 5.00 & 10.00 & Konczewicky \\
\hline 3.79 & 2.47 & 0.8 & 3.18 & 1.09 & 6.31 & 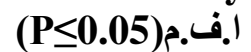 \\
\hline
\end{tabular}

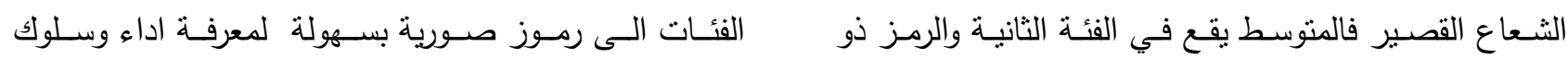
التراكيب الوراثية ضمن اعلى تغاير لصفتنن وامكانية تصنيف

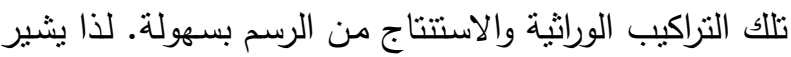

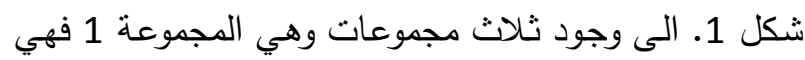

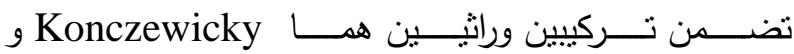
Zwyczajyny

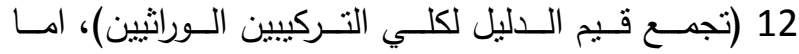
المجموعة الثنانية فتضمنت اربعة نراكيب وراثية هي موصل (16) وبري (16) وسوري (13) ومنتخب جيل1 (12). بذا نـاند يكون مجموع قيم دليل هذه المجموعة 57. الثالثة فقد احتوت تركيب وراثي واحد هو البلدي ذو قيم دليل 14. لذا يكون مجموع قيم دليل هذه المجموعة 14. لذا تقترح النتائج ان التحليل الصسوري Metroglyph قد يكون ملانـم لتجميع التراكيب الوراثيـة لاي محصول (7 و 14). قد تكون

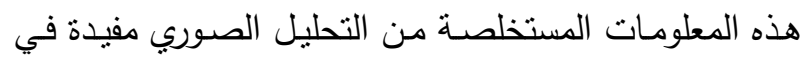
برامج التربية لتحسين محصول الكراوية مستقبلا. اذ يتوقع ان الثعاع الطويل يعني ان المتوسطات تقع ضمن الفئة الثالثة. هذا يعني ان المتوسط لاي صفة اذا كان يساوي متوسط الفئة

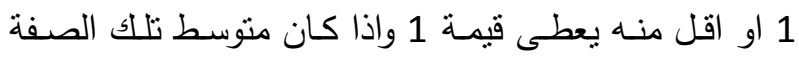
يساوي المتوسط في الفئة 3 او اكبر منه يعطى قيمة 3 واذا كان متوسط الصفة يقع مدي متوسطي الفئتين يعطى قيمة 2 وهو ما يسمى بقيمة الدليل index score (جدول 3). يظهر ماني جدول 3 اداء كل تركيب وراثي من محصسول الكراويا الذي لني يتمثل بالمجموع الكلي لقيم الدليل المستخلص من مجموع قيم

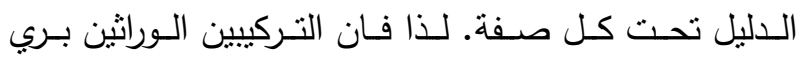
وموصل قد حققا اعلى قيم دليل بلغ 16 لكل منهما، تلاهما

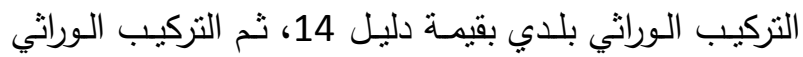

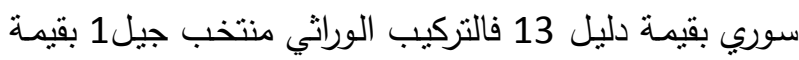

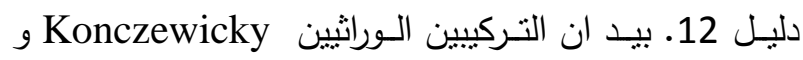
Zwyczajyny

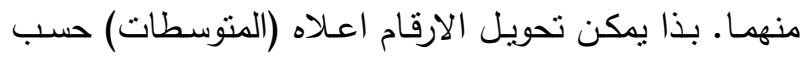


التراكيب الوراثية المجمعة في مجاميع مختلفة يمكن ان تحقق

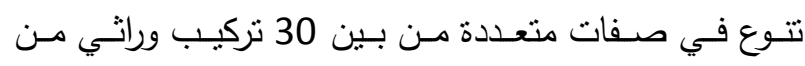
محصول الحمص. كذلك ان تلك التراكيب الورانيـة المختلفة فئة

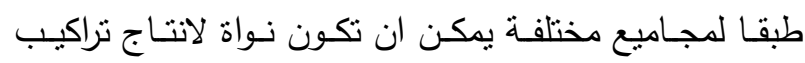
وراثية اخرى متحملة للملوحة لمحصول القطن (3). قد تساعد هذه الطريقة في اعادة ترتيب التضريب للحصول على افضل ملثل

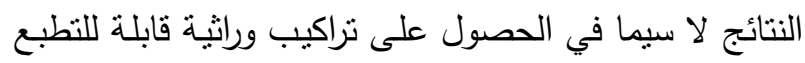
لمحصول الخردل الهندي (17). كما استخلص Dhaliwal و Mittal (9) بعض التراكيب الوراثية لمحصول فستق الحقل التي يمكن ادخالها في برامج التهجين لتوليف بعض الصفات

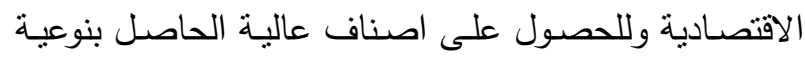

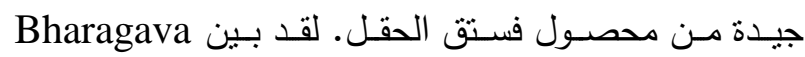

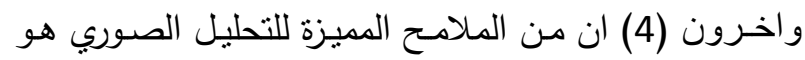
توزيــع نـوعي الرغيلـة Chenopodium album والكينـوا C.quinoa الورانية في تعبير صفاتها من المتوسطة الى العالية.
يعطي التضريب بين المجموعة الثانية والثالثة افضل النتائج. المجموعـة ذات اقل قيم دليلـ (12) هـي المجموعـة 1 التـي

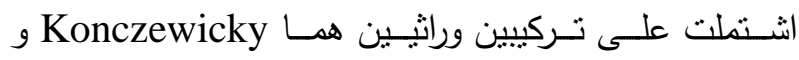
Zwyczajyny

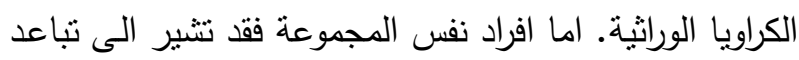

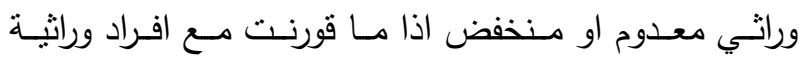
لمجموعات اخرى. لذا فالتضريب بين افراد المجموعة نفسها قد لا يعطي افراد انعزالية جيدة. بذا فالتضريب بين افراد من مجاميع مختلفة ذات قيم دليل عالية قد تعطي افراد مرغوبة. بالمثل فاذا رغب شخص مـا في تحسين صفة ما قد تكون غير مرغوبـة او ضـعيفة في تركيب وراثي معين فـان هذه فئه المعلومـات مفيدة في تحديد التضـريبات التي تحقق النتائج المرغوبة. فقد اكد Datta واخرون (7) ملائمة هذه التقانة في تصنيف اولي لعدد كبير من سلالات الذرة الصفراء. من هذه

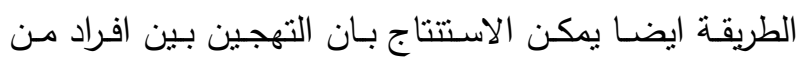

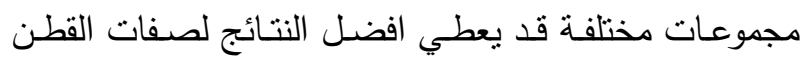

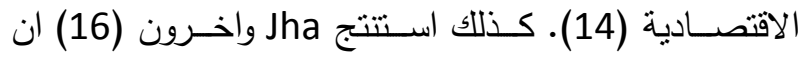

جدول2. معامل الاختلاف ومديات متوسطات الصفات وفئات قيم الاليل لنبات الكراويا المزروع في العرلق

\begin{tabular}{|c|c|c|c|c|c|c|c|}
\hline 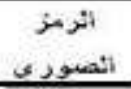 & 3 & 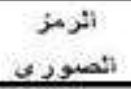 & 2 & ألثربز & 1 & c.v.\% & أتصفة \\
\hline$\oplus$ & 44.32 & $\oplus$ & $\begin{array}{c}11.66= \\
44.32\end{array}$ & $\oplus$ & 11.66 & 9.1 & أرتقاع أثنيات \\
\hline$\oplus$ & 11.66 & $\oplus$ & $\begin{array}{l}8.33 . \\
11.66\end{array}$ & $\oplus$ & 8.33 & 8.1 & عدد الخمرع \\
\hline$\oplus$ & 34.66 & $\oplus$ & $\begin{array}{l}22.33 . \\
34.66\end{array}$ & $\oplus$ & 22.33 & 9.6 & عدد الثنورأت \\
\hline$\oplus$ & 8.32 & $\oplus$ & $\begin{array}{l}6.66 \\
8.32\end{array}$ & $\oplus$ & 6.66 & 6.8 & فطر اثلنوريسة \\
\hline$-\oplus$ & 15.32 & $\oplus$ & $\begin{array}{l}12.66= \\
15.32\end{array}$ & $\oplus$ & 12.66 & 12.1 & عدد الثنور أت \\
\hline$Q$ & 26.62 & $\oplus$ & $\begin{array}{l}18.31- \\
26.62\end{array}$ & $\oplus$ & 18.31 & 12.7 & حاصن الثنبات \\
\hline
\end{tabular}

جدول 3. قيم الاليل لبعض الصفات المورفولوجية لسبعة تراكيب وراثية من الكراويا المزروعة في العراق.

\begin{tabular}{|c|c|c|c|c|c|c|c|}
\hline المجموع الكلي & حاصل النبات & عدد النوريةات & قطر النورة & عدد اللنورات & الافرع & النبات & التراثيبة \\
\hline 12 & 2 & 2 & 3 & 1 & 1 & 3 & منتخب جيل1 \\
\hline 14 & 3 & 3 & 3 & 1 & 1 & 3 & بلاي \\
\hline 16 & 2 & 3 & 3 & 3 & 2 & 3 & بري" \\
\hline 16 & 2 & 3 & 3 & 2 & 3 & 3 & موصل \\
\hline 13 & 2 & 2 & 3 & 2 & 1 & 3 & سوري \\
\hline 6 & 1 & 1 & 1 & 1 & 1 & 1 & Zwyczainy \\
\hline 6 & 1 & 1 & 1 & 1 & 1 & 1 & Konczewicky \\
\hline
\end{tabular}




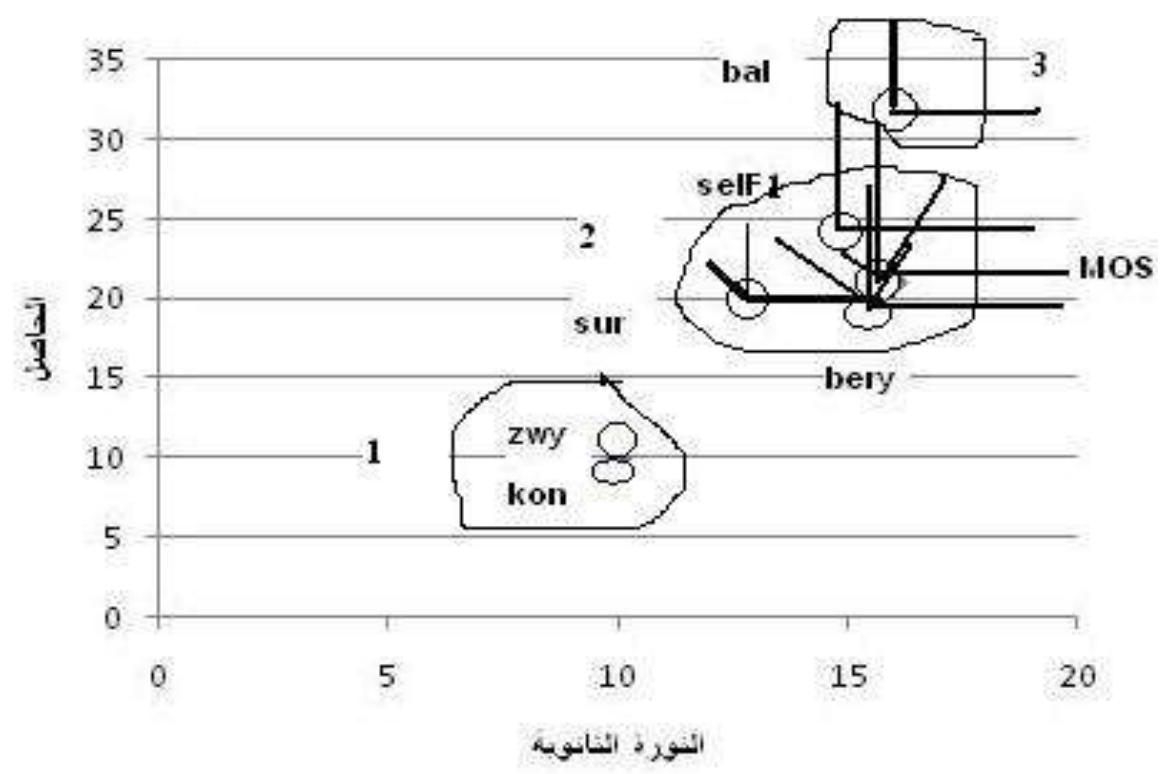

شكل1. التمثيل الصوري بتقانة Metroglyph لسبعة تراكيب وراثية من الكراويا المزروعة في العرلق. Bal = بلاي و MOS = موصل و Bery = بري و selF1 = منتخب جيل1 و sur = سوري و Zwyczajyny = zwy و

\section{Konczewicky}

\section{REFERENCES}

1.Almehemdi, A.F. 2011. Effect of Sowing Dates, GA3, some Plant Extracts and Vitamins on Ggrowth and Yield of two Caraway Cultivars. Ph.D. Dissertation, Field Crop Science Dept., college of Agriculture, University of Baghdad, IRAQ.

2.Anderson, E. 1957. A semi-graphical method for the analysis of complex problems. Proc. Natn. Acad. Sci. Wash. 43: 923-27.

3. Aslam, M., S. M.A. Basra, M. A. Maqbool, H. Bilal, Q. U. Zaman and S. Bano.2013. Physio-chemical distinctiveness and metroglyph analysis of cotton genotypes at early growth stage under saline hydroponics Intl. J. Agric. Biol. 15(6): 1133-1139.

4.Bhargava, A., S.Shukla, R.Kumar and D .Ohri. 2009. Metroglyph analysis of morphological variation in Chenopodium spp. World J. Agric. Sci. 5(1): 117-120.

5.Bocianowski,J. and K.Seidler-Lozykowska. 2012. The relationship between RAPD markers and quantitative traits of caraway Carum carvi L. Indust. Crops Prod. 36: 135-139.

6.Dabkevicius, Z., B.Gelvonauskis and A.Leis -trumaite. 2008. Investigation of genetic resources of cultivated plants in Lithuania. Biologija 54: 51-55.

7.Datta,D.,B.K.Mukherjee,N.S.Barua and S.P .Das. 2013. Metroglyph analysis of maize (Zea mays L.) inbreds for preliminary classification and group constellation. Afr. J. Agric. Res. 8(45): 5659-5663.

8.Dehghani, F., M.R.Panjehshahin and Z.Vojdani. 2010. Effect of hydroalcoholic extract of caraway on thyroid gland structure and hormones in female rat. Iran. J. Veter. Res. 11(4): 337-341.

9.Dhaliwal,G.P. and V. P.Mittal. 2011. Semigraphical analysis of yield and components in groundnut (Arachis hypogaea L.) genotypes. Crop Res. 41 (1, 2 \& 3): 197-200.

10.Eddouks,M., A.Lemhadri and J.B. Michel. 2004. Caraway and caper: Potential anti-hyper glycaemic plants in diabetic rats. J. Ethno Pharmac. 94: 143-148.

11.El-Labban, H.M., A.A.Gad, F.A. Sadek and R.S.F. El-Serafy. 2011. Improving some economic traits of caraway Carum carvi L. through mass selection. J. Plant Prod. 2(12): 1783-1790.

12.Ene,A.C.,E.A.Nwankwo and L.M. Samdi. 2007. Alloxan-induced diabetes in rats and the effects of black caraway Carum carvi L. oil on their body weight. Res. J. Medic. Med. Sci. 2: 48-52.

13.Ferrie,A.M.R.,T.D.Bethune,G.C. Arganosa and D.Waterer. 2011. Field evaluation of doubled haploid plants in the Apiaceae: Dill (Anethum graveolens L.), caraway (Carum carvi L.) and fennel (Foeniculum vulgare Mill). Plant Cell Tiss. Organ. Cult. 104: 407-413. 
14.Haidar, S.M. ASLAM, Mahmood-ULHassan,H. M. Hassan and Allah-Ditta.2012. types for different economic traits and response to cotton leaf curl virus (CLCV) disease. Pak.J.Bot. 44(5): 1779-1784.

15.Jafari,B. 2011. Influence of caraway on improves performance and blood parameters of Japanese quails. Annals Biol. Res. 2(6): 474-478.

16.Jha, U.C.,D.P. Singh1, P. J. Paul and G. R. Lavanya. 2011. Metroglyph Analysis for Morphological Variation in Chickpea (Cicer arietinum L.). Madras Agric. J., 98 (4-6): 121-123.

17.Khan, F.A.,M.Younas and G. Mustafa. 2005. Metroglyph analysis for the yield and quality related characters of Brassica juncea L. Intl. J. Agric. Biol.7(2):260-262.

18.Lahlou, S., A.Tahraoui, Z.Z.Israili and B.Lyoussi. 2007. Diuretic activity of the aqueous extracts of Carum carvi and Tanacetum vulgare in normal rats. J. Ethnopharmac. 110: 458-463.

19.Laribi, B., N.Zoglami, M.Lamine, K.Kouki, A.Ghorbel and A.Mougou. 2011. RAPD-based assessment of genetic diversity among annual caraway Carum carvi L. populations. Eurasia J. Biosci. 5:37-47.

20.Lemhadri, A., L.Hajji, J.Michel and M.Eddouks. 2006. Cholesterol and triglycerides lowering activities of caraway fruits in normal and stroptozotocin diabetic rats. J. Ethnopharmac. 106: 321-326.

21.Naderi-Kalali, B., A. Allameh, M.J. Rasaee, H.J. Bach, A. Behechti, K. Doods, A. Kettrup and K.W. Schramm. 2005. Suppressive effects of caraway Carum carvi extracts on 2, 3, 7, 8- tetrachlorodibenzo- p- dioxin-
Genetic diversity among upland cotton geno

dependent gene expression of cytochrome P450 1A1 in the rat H4IIE Cells. Toxic. In Vitro 19: 373-590.

22.Nemeth, E. 1998. Caraway: The Genus Carum. Harwood Academic Publishers, Amsterdam. The Netherlands.

23.Petraityte, N. 2003. Ex situ stability of morpho-biochemical properties of common caraway Carum carvi L. Ekologija 1:43-46.

24.Petraityte,N. and A.Dastikaite. 2007. Agrobiological assessment of wild Carum carvi L. cenopopulation biodiversity ex situ. Biologija 53: 74-79.

25.Rao,G.V., T.Annamalia, C.Shalene, T.Mukhopadhyay and M.S.L. Madhavi. 2011. Secondary metabolites and biological studies of seeds of Carum carvi L. J.Pharm.Res. 4(7): 2126-2128.

26.Roy,S.D.,S. Thakur, A. Negi, M. Kumari, N. Sutar and G.K. Jana. 2010. In vitro antibiotic activity of volatile oils of Carum carvi and Coriandrum sativum. Intern.J. Chem. Analyt. Sci. 1(7): 149-150.

27.Seidler-Lozykowska,K. and J. Bocianowski. 2012. Evaluation of variability of morphological traits of selected caraway Carum carvi L. genotypes. Ind. Crops Prod. 35: 140-145.

28. Toxopeus, H. and H.J. Lubberts. 1994. Effect of genotype and environment on carvone yield and yield components of winter-caraway in the Netherlands. Ind. Crops Prod. 3(1-2): $37-42$.

29.Zakharova, E.A. 2010. Morphological evidence of polyphyletic nature of traditional Carum (Apiaceae-Apioideae). Plant Div. Evol. 128(3-4): 409-421. 